\title{
Sustainable development through climate action
}

\author{
Parties to the Paris Agreement must increase their ambition, but stringent climate policy has the potential to \\ put sustainable development at risk. A collaborative effort is underway to identify potential trade-offs and to \\ strengthen synergies between climate action and sustainable development.
}

\section{A} fter three years of negotiations, the 2030 Agenda for Sustainable Development was launched in September 2015 as the successor to the Millennium Development Goals. While the 17 goals and 169 targets comprising the Sustainable Development Goals (SDGs) are, in many ways, the sequel to the Millennium Development Goals, they represent a clear departure from the previous agenda, which was criticized for being too narrowly focused on North-South relations and poverty reduction, and for taking a technocratic approach ${ }^{1}$. The SDGs represent a shift to a more holistic and wide-ranging agenda for global sustainable development, but this broader scope presents new challenges arising from interactions between different goals and targets.

There are competing agendas, interests and priorities among the entwined economic, social and environmental protection goals. Some research suggests there are more synergies than trade-offs within and among the SDGs in most countries $^{2}$, but the deep socio-technological transformation implied by strong climate action (SDG13) presents a unique challenge for development. Climate mitigation policies could slow economic growth, negatively change industrialization, exacerbate inequality and poverty, and impact the social and economic drivers of conflict in some countries ${ }^{3}$. At the same time, the Paris Agreement's goal of holding global average temperature to well below $2{ }^{\circ} \mathrm{C}$ above preindustrial levels, necessitates strong mitigation policy. However, it is not necessarily the case that high ambition equals more trade-offs. In fact, some research suggests that there are fewer co-benefits from less ambitious short-term climate policy than there are from more ambitious strategies ${ }^{4}$.

Importantly, both the Paris Agreement and SDG13 include efforts to strengthen resilience and foster adaptive capacity. Sustainable development trade-offs and synergies with adaptation are as important as trade-offs and synergies from mitigationoriented energy system change. In this issue, Jon Hellin of the International Rice Research Institute (Philippines), and Eleanor

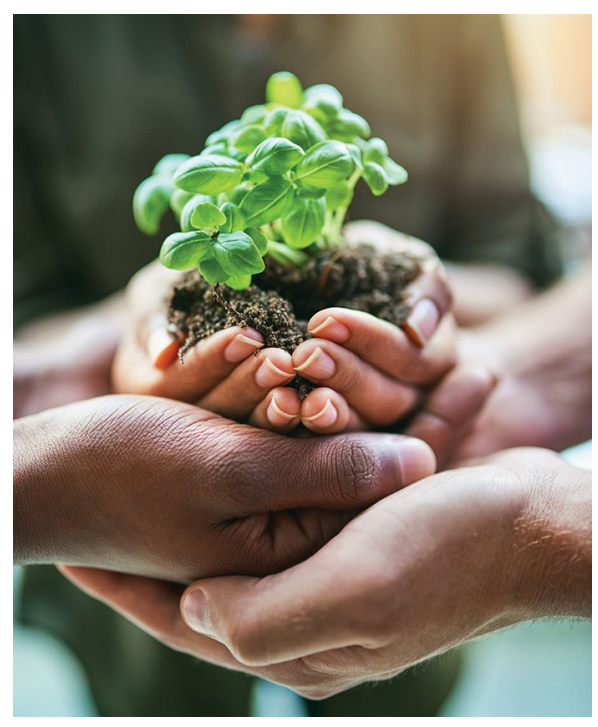

Credit: Peoplelmages/E+/Getty

Fisher of the University of Reading (United Kingdom), raise concern in a Comment that the set of agricultural technologies and practices known as climate-smart agriculture run a real risk of failing to reduce poverty (SDG1), achieving gender equality (SDG5) or reducing inequality (SDG10).

Even if climate-smart agriculture does not directly impact food security (SDG2 seeks to "End hunger, achieve food security and improved nutrition, and promote sustainable agriculture"), it has the potential to reinforce existing livelihood inequities.

Potential synergies and trade-offs are also on the minds of policymakers. In April 2019, the United Nations Department of Economic and Social Affairs and the United Nations Framework Convention on Climate Change jointly hosted a 'Climate \& SDGs Synergy Conference'. The stated goal of the conference was to analyse gaps and challenges regarding trade-offs in pursuing the 2030 Agenda and Paris Agreement objectives, and to develop concrete recommendations for strengthening synergies. We caught up with representatives of Thailand, Costa Rica and the Democratic Republic of Congo, who attended the conference to discuss how their countries are working to manage the trade-offs and leverage synergies between climate action and the pursuit of sustainable development. Both the challenges faced, and the approaches to addressing them, are diverse. For some, guaranteeing access to affordable and reliable energy (SDG7) while transitioning away from fossil fuels is a potential challenge, while others see challenges in financing and organizing partnerships to pursue the goals (SDG17).

Efforts are needed to scale up both SDG and Paris Agreement policies, but the global community is engaged and largely optimistic about the challenges ahead. The United Nations Under-Secretary-General for Economic and Social Affairs, Liu Zhenmin, and Patricia Espinosa, the Executive Secretary of the United Nations Framework Convention on Climate Change, make a call in this issue for raising climate ambitions in pursuit of sustainable development. Although the Paris Agreement and the 2030 Agenda are not perfectly aligned, they are fundamentally in pursuit of the same goal - a better, healthier and more resilient life for present and future generations. The April conference was a first step. Multilateral meetings through the remainder of the year look to carry momentum forward. Zhenmin and Espinosa call on nations to prepare updated Nationally Determined Contributions that reflect the need for urgent action, accelerate full implementation of the Paris Agreement, and raise ambition for climate and development finance.

The literature is growing, but further research is needed for a comprehensive view of how specific climate actions intersect with, or otherwise hinder, pursuit of the broader sustainable development agenda, as well as to understand best practices for strengthening synergies. Nevertheless, the Paris Agreement and the 2030 Agenda should not be viewed as incompatible.

Published online: 25 June 2019 https://doi.org/10.1038/s41558-019-0528-3

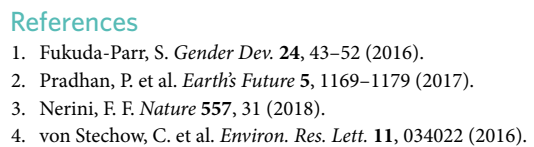

